\title{
Revisiting Development of a Multi-Paradigmatic Model for Environmental Socialization of an Individual in a Multi-Cultural Environment
}

Asiet Nurbievna Autleva

Kazbek Dovletmizovich Chermit

Fatimet Pshimafovna Khakunova

Aminat Amerbievna Afashagova

Khatkov Aliy Mossovich

Federal State Budget Institution of Higher Professional Education «Adyghe State University» (ASU) 385000, Maikop, street Pervomayskaya, 208, Russian Federation

Email: nisadgu@yandex.ru

Doi:10.5901/mjss.2015.v6n5s1p258

\section{Abstract}

The article covers the theoretical and methodological basis for the development of a multi-paradigmatic model for environmental socialization in a multi-cultural educational environment via the system of existential, pragmatic and resonancesynergetic paradigmatic models characterized by their own objectives, content, technological approaches and criteria in effective searches. The article demonstrates that the development of conceptual multi-paradigmatic model for environmental socialization of an individual in a multi-cultural educational environment derives from the need in the search of new models for environmental education and upbringing of learners based on the acknowledgement of a multi-paradigmatic nature of modern culture with education being a significant part of it; coexistence of different ways of world interpretation from the point of view of cultural and educational pluralism. The use of the system of existential, pragmatic and resonance-synergetic paradigmatic models in developing a multi-paradigmatic model for environmental socialization in a multi-cultural environment stipulates for the application of combination of methods, integrative ideas, and methodological principles being the methodological regulators for all units of this system. The article justifies the essence of the multi-cultural educational environment as a subjective context of an individual that is used to communicate social and individual experience in application of the culture of attitude to nature. Educational environment as a medium for learners' existence contains Events, dominant ideas of various significance resulting in resonance impulses intensified under observance of certain conditions required for stimulation of resonance mechanism; the resource potential of multi-cultural educational environment in the process of environmental socialization has been detected, acting as a determinant for provision of environmental socialization.

Keywords: environmental socialization, multi-cultural educational environment, national values, ethnical traditions, environmental imperatives, paradigm, multi-paradigmatic approach, resonance interaction, resonance, synergetics, existential paradigm, pragmatic philosophy.

\section{Introduction}

The relevance of development of a multi-paradigmatic model for environmental socialization of an individual is in the acknowledgement of objective geo-political, cultural, social, and educational transformations in the world in the context of global multi-cultural environment resulting in the need of searches on invariant problems the solution of which is relevant for the development of a modern life paradigm implementing the ideas of Sustainable Development concept. In this case the harmonization of the "human-nature-society" system may become a common problem for all states. In line with the above, there is also an objective need in the search for new models for environmental education of learners based on acknowledgement of multi-paradigmatic essence of modern culture with education as an integral part of them; this results from the availability of various ways of interpretation of the world from the point of view of cultural and educational pluralism.

The new ideology connected with the attitude of a human to nature is based on transdisciplinary understanding of the existing contraposition of natural and social in real world and indicates the necessity of searching for new approaches 
to the development of the system of environmental education of population complying to all modern global and local environmental challenges.

Under condition of announcement of democratic principles in the state structure of modern Russia the role of ethnical and cultural identity becomes more important resulting in strengthening in the development of an ethno-cultural factor ensuring nature and culture oriented activities in educational practice.

As a sociocultural phenomenon, education is considered one of specific forms of socialization of an individual. Under current conditions, educational establishments have to on the one hand change the priorities in the lifestyle of an individual to meet the ideas of co-evolution of an individual and nature and on the other hand to preserve national and ethnical traditions as a condition for environmental problems solution in the multi-cultural world.

Conceptual multi-paradigmatic model has to include objective and subjective factors and conditions which integration ensures acceptance by an individual of environmental knowledge, meanings, and values considered as moral imperatives.

Following the assumption that a multi-paradigmatic approach is a "theoretic and methodological strategy of modern social research", Yadov V.A. (2006) considers it expedient for "combination of various theoretic approaches" that is, to a greater extent, adequate to the new "historical and cultural science stage."

Kolesnikova I.A. (1999) introduced the notion of "paradigmatic plurality" enabling to "overcome rigid borders of paradigmatic restrictions established in science... Co-existence of various paradigmatic environments does not disturb the integrity of educational reality; moreover, it contributes to its development through the increase of diversity; interparadigmatic method of reflecting such plurality serving as a method of cognition, implemented at the level of reflection will be adequate to inhomogeneity of its structure (Kolesnikova, 2003). The author attributes an epistemological function to paradigmatic plurality: inter-paradigmatic reflection lifts all restrictions regarding the ways of understanding of the essence of life developed as part of the considered subject. Herewith, we do not get certain averaged integrative truth but an understanding of the sources of various paradigmatic views.

Educational feasibility of a multi-paradigmatic approach lies in the fact that it allows to cover event-related reality of the subject of education in its diversity and inconsistency in conditions. "...We accumulated unique experience in mutual influence, enhancement, and respect of various cultures. Such multi-culture and multi-ethnicity is present in our historical consciousness, in our spirit, our historical code" (Putin, 2014).

Moral imperatives of national values, regulating and governing the attitude of an individual to nature can serve as the Basis of such unity. According to Moiseyev N.N. (1995), "...the society feels the need in the distinctive environmental imperative as an aggregate of conditions and prohibitions, which implementation may ensure survival of a human, further progress of humanity and its common evolution with nature." Such environmental imperative arises mainly due to such social institution as education, as part of which the understanding of objective laws of development of the "nature-human" system occurs (Moiseyev, 1995).

The methodological basis of analysis of interaction of two complex systems "nature" and "human" in the social and cultural environment under consideration is the category of "lifestyle". This level of routine forms deep foundations of a human - thinking, values, mentality, determining responsible attitude of a human to him/herself, environment and nature. Under modern conditions, the survival of a human largely depends on the development of global environmental culture combining the values of national cultures and human values.

"Development of a new lifestyle where the individual chooses the life path based on environmental paradigm is an expected result of environmental socialization. Efficiency of such interaction between the subjects of multi-cultural environment is characterized by the establishment of a cultural dialogue" (Autleva, 2014). Educational environment in which the environmental imperatives of ethical values are actualized (nature preservation, conservation and self-value), subjects of multi-cultural environment (norms, values, visions, and perceptions), may become an important resource for development of moral attitude of the individual to the environment.

Makayev V.V. (1999), and Suprunova L.L. (2014) interpret multi-cultural educational environment as "personal environment since the main subject of its implementation is the learner; it is a dialogue-based environment since only dialogue-based relations ensure full-scale interaction of various sub-cultures."

Numerous paradigms applied for the development and implementation of the system of environmental socialization formation determine a set of research methods and implementation techniques for each paradigmatic model (existential, pragmatic, resonance - synergetic) along with the search of integrative ideas, invariant methodological principles of construction and transformation of educational environment, which precondition integration of the integral multiparadigmatic model while maintaining the autonomy of each conceptual model. 


\section{Methods}

Multi-paradigmatic approach to the development of the system for environmental socialization of an individual in a multicultural educational environment preconditioned application of specific methods of multi-paradigmatic analysis research (comparison, determination of similarities and differences in paradigmatic models), forecasting methods (juxtaposition and extrapolation of experience in organization of environmental education and upbringing in native science and practice as well as in foreign systems of education aiming at justification of conditions for the development of multi-paradigmatic models and their forecasting), methods of expert evaluations, forecasting methods (registration inspections, control tests), methods of mathematic statistics.

\section{Results and Discussions}

Development of a paradigmatic model resulted from a paradigmatic analysis characterized by the dialectic integrity of its internal systems, i.e. internal complex models - existential, pragmatic, resonance-synergetic. In addition, the paradigmatic analysis is based on the method of similarity and difference, which shows that none of them is self-sufficient as it involves values and meanings from other paradigms. Herewith, different levels of adequacy related to socio-cultural needs of the society as well as multi-directionality characteristic of the educational process and principal paradigms pertaining to modern educational system - all of them are based on humanistic grounds and have cross-over points; this results in their mutual enrichment and appear in interpretation of the main objective of education - formation of a complete creative individual aiming at actualization of cultural and ethnical values, meanings, behavioral models of society compliant with the ideas of nature preservation and harmonious balance in the system "human-nature-society".

Hence, the systematization of innovative educational development strategies in the modern system of education is possible only in the context of all methodological approaches to be determined in the course of comparison analysis of their theoretical and methodological integration and interaction.

Multi-paradigmatic approach as a research method used for the development of educational system of formation of environmental values for learners under conditions of multi-ethnical educational environment is based on the principal "theoretical possibility of connection or combination of historically acknowledged methodologies in a common space-time continuum" (Chermit \& Autleva, 2014).

As part of multi-paradigmatic approach, we conducted a research on essential features of development of multiparadigmatic model for environmental socialization of an individual in a multi-cultural educational environment (multicriteriality, nonlinearity, selectiveness, general purposefulness, adjustability, feasibility).

"Different nature of values in each of the paradigms results in various systems of standardisation, assessment of quality and evaluation of educational results. The environment for the objectives formation is over-individual and oversocial since it relates to transcendental reality and is out of time" (Kolesnikova, 1999).

Each of the above paradigmatic environment is characterized by a different educational objective.

Thus, in pragmatic paradigm the objective is set "outside", "externally" and determined by feasibility based on social demand and utility. In existential paradigm, the objective is set "inside the educational system at interception of subjective realities, in inter-subjective environment as a result of agreement of meanings of all subjects of educational environment (Budanov, 2003).

\subsection{Ideology of existential paradigm as the basis of environmental socialization model in a multi-cultural educational environment}

Existential paradigmatic model of environmental socialization is characterized by an individual, existential-oriented approach, which originates from post-non-classical culture that determines the picture of the world today, sets knowledge benchmark and methodological tools for the research.

Heidegger M. (1988) specifies "questioning", "location", "nesting", "life care" as personality existentials; Sartre J.P. (1990) - "personal responsibility", "personal freedom", "personal choice", "search of own self"; Berdyayev N. (1990) "creativity", "spirituality", "freedom", "responsibility"; Fromm E. (2009) considered "love", "hope", "strength", "conscience", "spirituality", "happiness" principal personality existentials.

Existentials develop upon interaction in the systems of "human-human", "human-society", "human-nature" in such neoformations of personality as "responsibility", "oughtness", "conscience", environmental conscience", "environmental sensibility", oughtness", etc. For example, oughtness is a moral prescription: after a certain choice is made as part of natural necessity, an individual is morally responsible to preserve balance in nature. 
The following may be attributed to personality existentials in the process of environmental socialization: emotions, feelings, empathy, responsibility, environmental conscience, attitudes, and motives.

In the existential paradigm the most important are the feelings of moral character. "A human is in the center of moral feelings; eventually, moral feelings show - in the form of affection - relation of an individual to others, to the society; their variety reflects the diversity of human relations. Moral feelings derive from social lifestyle of people. Every feeling as an affection reflects something more important for an individual; in moral feelings there is something objectively important for the society which is at the same time perceived as important for personality" (Prohovnik, 2006).

Traditional understanding of existential approach to the analysis and development of educational practice is characterized by focusing of an individual on him or herself, or implied reference to the mechanisms of self-development, self-knowledge, and self-improvement. From this point of view, of particular importance is the methodological understanding of the function of the social environment in providing significant impact on the formation of the person through the mechanisms of self-determination. This means that the person is not only determined but self-determined.

Based on the developments of Yaroslavl School of Science and Education under the aegis of Rozhkov M.I. (2000) we distinguish the following principles of existential pedagogics and apply them in development of the existential paradigmatic model for environmental socialization of an individual:

- the principle of self-development encouragement is aimed at educational methods of self-education determination, self-upbringing, self-awareness, self-identity. As a result, learners master the methods of selfawareness, reflection, planning life events in the process of mastering of social, environmental, ethical norms as moral imperatives of attitude to nature;

- the principle of moral self-regulation envisages provision of educational assistance to learners in carrying out moral evaluation and moral choice in the process of learning and tackling of social and environmental problems, situations, and events. Understanding of moral norms in social environment and their reflection results in further development of the content of such existential properties of an individual as "responsibility", "conscience", "feelings", "values" and their hierarchy from the point of view of their importance and their application in a day-to-day life;

- the principle of situation actualization envisages that each educational Event contains a situational dominant being an actualized internal state of a person determining in the content of such Event something of importance for a person and that is reflected in a person's emotional evaluation. During the performance of activities and communication it is advisable to focus the attention of the subject of socialization on the side of an Event that has a higher educational potential. Herewith, the situational dominant is logically connected with the person's emotional evaluation of Events since it is aimed at development of emotional sphere: empathy, feelings.

\subsection{Ideology of pragmatic paradigm as a basis for the model for environmental socialization of an individual in a multi- cultural environment}

Pragmatic paradigm as a basis for the model for environmental socialization of an individual in a multi-cultural environment is characterized by its social and practical focusing that is feasible from the educational point of view in formation of environmentally socialised individual. Pragmatic model for environmental socialization of an individual in a multi-cultural environment is based on pragmatic philosophy; its basic ideas determine the general parameters, characteristics of the model. (It should be noted that the educational models developed by Soroka-Rosinskiy V.N. (1991), Makarenko A.S. (1984), Shatskiy S.T. (1980) were particularly focusing on practices aimed at civil education, development of active life philosophy).

The specifics of environmental awareness can be seen in the fact that it is outside the scope of subject knowledge, as it is closely related to the need of demonstrating an active life position of an individual in the evaluation and the search of environmental problems solutions. The objective of a pragmatic paradigm model for environmental socialization of an individual in a multi-cultural educational environment is to teach the learners to solve real environmental problems.

Significant changes in the sphere of politics and economy of western societies in the middle of the XX-th century served as prerequisites for the development of a pragmatic educational model. In response to those challenges, the developments in the area of philosophy of pragmatism by Peirce (2000), Dewey J. (1921) later became methodological ground for the educational system in foreign countries. In this respect, the history of pragmatic paradigm development differs from the cultural one by the fact that it focuses not on the events resulting from acts of humans, but from the state of societies deriving from material, intellectual, moral, and social relations; this connects specific facts not as causes and effects, but as a transition from one form to another. 
According to this logic, any social history, facts, and events can be divided into pragmatic (events and human actions in them) and cultural (the state of society and forms of life, ways of husbandry), with a pragmatic (causal) or evolutionary component being the link between them. Dewey J. (1921) was the founder of the philosophy of pragmatism. The philosophy of pragmatism is based on two principal ideas: the theory of doubt and faith; and the theory of value.

As part of a pragmatic model for environmental socialization of an individual, understanding of the subjects of environmental socialization involves assessment of the performance or ability to perform in future any social role in the harmonisation of the "human - nature - society" system.

Solving real environmental issues as personal life problems will be ensured via:

- understanding and comprehension of methods aimed at solving common social and environmental issues;

- accumulation of experience in solving environmental issues as life problems;

- inclusion of the individual in the social world through the mastery of projective skills, practical ways to transform social reality in the direction of maintaining the environmental balance;

- developing readiness in a learner to actively search for the ways of improvement of environmental situation.

Recording and implementation of a problematic aspect of environmental knowledge requires constant accumulation, and, most likely, recovery of the previous experience of a learner, where the "attitudinal" nature of environmental awareness is based on the emotional and sensual sphere of a human, reflection, and the perception of nature. All new emotions, feelings, and senses are based on the recovery of life experience of the learner: "I saw this", "I felt this", "I like this", etc. This results in development of a new life style where the integration of ethnical and environmental ethics becomes prerequisite for the development of environmental imperatives with regard to the human and environment in which he/she lives.

Development of pragmatic paradigmatic model for environmental socialization at the stages of actualization, recovery and accumulation of the learner's personal experience.

The mechanism of experience accumulation is presented at the level of accumulation of personal experience or the experience of social environment, ethnos. The nature of experience is largely determined by its source. Social experience forms grounds for personal experience as an experience of a specific individual forming his/her individual culture.

Social experience of ethnos has a lot of levels and hierarchies that are dialectically interdependent; they determine the content of different cultures forming the experience of a human as a panhuman culture. Personal experience is interconnected with the aggregate experience of community via a joint activity of its members: here the conditions of a group reference and meaningful eventfulness should be complied with. Personal experience is also connected with a panhuman experience via education and self-education. It goes without saying that all those interrelations are mediated by human emotions.

\subsection{The ideology of development of resonance-synergetic model for environmental socialization in a multi-cultural educational environment}

Resonance-synergetic paradigmatic model of environmental socialization is based on different theories and concepts in which we investigate the synergetic nature of environmental socialization. Theoretical background for development of resonance-synergetic model for environmental socialization of an individual in a multi-cultural educational environment are the theories, concepts devoted to the study of natural (biological), social-communicative, chemical, physical, informational and other systems common for a resonance mechanism due to their openness, non-uniformity, nonlinearity.

The main idea of the concept of environmental socialization of an individual is that multi-cultural educational environment has dual effect on the individual: on the one hand, it unifies and standardizes the identity, thus providing for social adaptation for it; and on the other hand it is aimed at preserving its social autonomy with cultural identity and the need for individual distinctiveness. Some of the methodologically important structural components of this model are a system of principles, their hierarchy, conditions for their implementation.

During the development of resonance-synergetic model we took into account various types of connections between the elements in the hierarchical structure of the educational system: connection of the resonance-synergetic model as a complex multi-level system; connection of substantive nature; connections reflecting the relationship of different scientific disciplines, as well as connections reflecting the interaction of the school with a variety of social institutions; connection of training and education in the system of general socialization; organizational and functional connections, organizational and activity, technology, communication and other connections. 


\subsubsection{System of educational principles applied for the development of resonance-synergetic model for environmental socialization in a multi-cultural environment:}

\section{Meta-principles:}

- principle of multi-paradigmality - envisages combination of different paradigmatic attitudes in developing the system of environmental socialization of an individual (humanistic rationalist, pragmatic, existential);

- principle of inter-disciplinarily - substantial component of this meta-principle results from integration of scientific knowledge, ethnic, ethical norms of ethno-cultural experience of nations, application of which by the subject of environmental socialization leads to the development of new environmental traditions and ethical norms.

The system of educational principles presented in our research consists of the three groups:

The first group contains the principles of development of a resonance-synergetic model for environmental socialization in a multi-cultural educational environment:

- principle of uncertainty is determined by synergetic understanding of the nature of interaction in the "humannature-society" system in a multi-cultural environment: nonlinearity, non-uniformity of the process of environmental socialization of an individual, ratio of traditions and innovations in the society, free and disciplined individual, norms and stereotypes, prohibitions and permissions; it envisages "uncertainty" in description of the means, borders of context, organization of influence (forces of influence, topology of influence, i.e. symmetry of topologic influence leading to familiarization of an individual with environmental imperatives at the stages of environmental socialization of an individual: actualization of experience, recovery and accumulation of experience.

- principle of integrity determines alignment of all structural components (sub-systems) of the resonancesynergetic model, envisages interdisciplinary integration of the means of development of a resonancesynergetic model for environmental socialization of an individual in a multi-cultural educational environment. Development of a technological algorithm ensures establishment of the system of self-management. The logic that is defined by the conceptual objective stimulates one of the resonance effects on a complex system of self-governed development as it initiates the operation of all structural subsystems, contributes to implementation of resource potentials of the system in general. Therefore, the integrity is followed by a systematic, complex learning of interconnected elements being part of this notion.

The second group contains the principles of enrichment of a multi-cultural educational environment with resource potentials:

- the principle of cultural feasibility includes recognition of education and upbringing as cultural phenomena and the content of education reflects universal panhuman, ethnic, environmental and individual cultural values.

- The conditions for implementation of the principle of cultural feasibility are as follows:

- coordination of interaction in the system of environmental socialization of all social institutions having a unilateral impact on the individual during the implementation of environmental imperatives of ethnical values;

- recording of environment factors: impact of ethnical, regional, corporate (educational establishments) on efficiency of environmental socialization.

The principle of multi-culture envisages:

- dialogue between the cultures of educational environment and subcultures of society that includes cultures of different ethnic groups, nations, social groups;

- establishing conditions for preservation and development of cultures ensuring development of general principles of people's attitude to environment.

The third group of principles for development of resonance-synergetic model includes the principles of synergetics:

- principles of interrelation of self-organization and organization, accidental and necessary. Self-organization serves as an objective basis for initiation of activity; organization is a mean for arrangement of a specific initiative in one form or another. Self-organization may result in negative consequences; hence, it requires modification and assistance on the part of school governing bodies and local authorities; it should focus on initiation and support of development processes, flexible arrangement of external factors;

- principles of resonance are efficient light resonance impacts on the controlled system. External impacts coincide (resonate) with internal mechanisms of self-organization;

- the principle of resonance is ensured in educational technologies by repeated intensification of any impact by: - use of various perception channels in the educational process, including audio-visual, multimedia; establishing the mode of periodical (routine) distribution of information at all levels of the environmental 
socialization system; - distribution of information in classes, school, family, reference group, sphere of leisure, youth policy, mass media, internet; - unidirectional impact of social institutions and their inclusion in educational environment of the school ensures extension of territorial, conceptual environment that influences the preservation of wave effect in distribution of information as a psychosocial factor initiating a chain reaction of resonance; distribution of a dominant idea (information) as a psychosocial factor via horizontal and vertical levels of the system; this complies with the principles of intensity, recurrent repetition, unidirectionality (consistency); compliance of message quality by complexity, significance, emotion and value content and other resources of an individual: knowledge, emotion and value, operation and activity; focusing of the message on a specific perception channel (demonstration of rhythmicity of information presentation) in accordance with the sensitive and perceptional features of an individual at different stages of ontogenesis; activation of available perceptions, social experience of the subjects of multi-cultural educational environment, i.e. information should comply with the perceptions that are already present in mass consciousness (recovery of social experience); exclusion of inconsistency of informational impulses, messages, opinions, managerial decisions, consistency and periodicity of information presentation allowing the information waves to overlap each other thus initiating the mechanism of resonance.

Consequently, the interrelation of educational principles ensures implementation of resonance-synergetic model that provides for favorable conditions for demonstration and development of cultural uniqueness of an individual i.e. actualizes the process of familiarization with environmental norms, environmental behavior, environmental stereotypes, traditions and customs for various ethnical groups.

3.4 Development of educational conditions for implementation of a multi-paradigmatic model for environmental socialization of an individual in a multi-cultural educational environment

- conceptual: environmental socialization of an individual in a multi-cultural educational environment constitutes the process of familiarization by an individual with social norms, values, traditions, relations, behavior based on environmental imperatives and means of social life, development of personal value system with respect to the environment in accordance with the environmental ethical norms;

- ideas of philosophy of existentialism, philosophy of pragmatism are taken as a methodological basis for the development of multi-paradigmatic model for environmental socialization of an individual; formation of an environmentally socialized individual is based on multi-paradigmatic, synergetic, systematic, culturological, resource, and contextual approaches.

- comprehensive: multi-cultural educational environment as the learners' life environment will be enriched by actualized environmental awareness, norms, traditions and values, environmental imperatives of ethnical cultures in the process of contexts-concepts formation, which application by an individual determines formation of an environmentally socialized individual;

- the possibility of personal or ethnical identification of the learners in the context of environmental socialization was provided, aimed at effective implementation of a multi-paradigmatic model (existential, pragmatic, resonance-synergetic) in accordance with the multi-vector setting of objectives in environmental socialization;

- specific social and cultural, environmental conditions of the area as life environment: ethnical traditions, traditions of lifestyle, mental peculiarities, attitudes of subjects within the limits of social environment have been taken into account;

- resource potential of social institutions is used to the full extent; mechanisms of their systemic and systematic impact and interrelation under conditions of actualization of environmental imperatives as moral invariants of ethno-cultural experience of a multi-cultural educational environment have been developed. Consequently, the resource potential of a multi-cultural educational environment becomes not only the established system of resources, but its new type that was not available before (or not applicable) with the possibility of its implementation scientifically justified and envisaged in the present research;

technological: the necessity of structural, contextual and organizational changes of educational, pedagogic, contextual, and environmental activity of general schools and their practical implementation has been justified; expansion of social context of learners due to inclusion of social institutions in it (family, mass media, Internet, biosphere reserves, schools for young naturalists, environmental centers, environmental and recreation camps, children tourism centers, national museums, culture and leisure complexes, municipal committees for education, etc.) in the mode of active search of innovative mechanisms of cooperation of the subjects of environmental socialization based on environmental, systematic and structural, synergetic, contextual, 
culturological, resource approaches.

The principle of multi-paradigmatics as part of the theory of conceptual modelling of the system of environmental socialization in a multi-cultural educational environment will be determined by:

multi-paradigmatic model (existential, pragmatic, resonance-synergetic) that represents a type of educational system development and envisages simultaneous modelling of locally dependent conceptual models; qualified characteristics and measured parameters of a multi-paradigmatic model of educational system are presented by its following structural components: target, contextual, technological and evaluation-diagnostic.

\subsection{Methodological vectors in development of a multi-paradigmatic model of educational system of formation are as follows:}

Multi-paradigmatic approach:

the system of paradigms serves as a mean for achievement of objectives at each stage of education thus ensuring obtaining of an integrative result in the process of implementation of such paradigms in the aggregate;

- the structure of each paradigmatic model has its own basic foundation that is included in and reflects essential integrity of all elements of the general system;

- availability in each paradigm for all basic foundations focusing on ethnical, environmental, general civil values and meanings, of its own valuable and autonomous foundations although each of such paradigms is in the state of complementarity, i.e. under conditions of complementarity resulting in the integrative state of educational environment;

- each of paradigms may set its own space-temporal vector in a multidimensional system of environmental socialization and determine the general strategy for its development.

Systematic approach in this research is determined by a phenomenon of environmental socialization of an individual in a multi-cultural educational environment: from theoretical point of view, this allowed to develop a common idea of environmental socialization of an individual and the idea of multi-cultural education. Systematic approach allows developing a methodology for educational environment, its educational structure and characteristics.

Synergetic approach to environmental socialization in a multi-cultural educational environment envisages determination of the ratio of traditions and innovations; ethnical and cultural variety; unification, tolerance and ethnical identity, normalization. Control of the system of environmental socialization taking into account the regularity of its development is aimed at the "launch" of a self-organization mechanism with an individual as its subject being the carrier of self-organization.

In developing a multi-paradigmatic model for environmental socialization of an individual in a multi-cultural educational environment a specific natural science concept determines the characteristics of a paradigmatic model since it explains, interprets the events, connections, phenomena not only in nature (biosphere), but in the "human-naturesociety" system.

Culturological approach in the system of environmental socialization in a multi-cultural educational environment allows considering the problem under consideration in the general cultural context: as an integration of an individual's culture with a culture of social relations. From this point of view, the culture of an individual and the culture of community represents an evolutionary developing, creative, mutually enriching objects. The dialogue of cultures is considered "an integration of different meanings (notions, samples) of cultures where the mind is focused on mutual understanding, communication via eras, via space and time, ensuring the encounter of high values of different cultures and means of their presentation" (Bibler, 1989). The culture in the context of our research is represented as an aggregate image of practical activity and value-comprehended lifestyle pertaining to one or another social, ethnical and educational environment. Their dialogueness is an important characteristic of modern culture in a multi-cultural educational environment, personal life of all learners.

Environment approach. As part of environment approach, a multi-cultural educational environment is envisaged in the form of different factors characterized by a complex nature of impact on an individual in the process of familiarization with scientific knowledge, ethical norms, evaluation meanings of environmental ethical norms comprised in ethical traditions and customs relating to attitude to environment in the process of environmental socialization.

Resource approach. It is known that the space and time context to a great extend determines ethical norms and "in its own way" interprets the attitude of an individual to nature. The borders of educational environment as a socialization field depend on its resources having a direct or indirect impact on the personality of a learner. During the life process an individual becomes the subject of social partnership. In characterizing the resource value of nature N. Reimers (1994) 
points out that this potential is comprised of the objects and events applied in the past, present and to be applied in future for direct or indirect consumption encouraging creation of material wealth, reproduction of labor resources, supporting the conditions for humanity existence and improving the quality of lifestyle.

We relied upon the provision that under the conditions of multi-cultural environment familiarization of an individual with the environmental ethics should be based, above all, on the values of "place development", i.e. on the values associated with the feeling of a personal life environment.

Event approach, on the one hand, characterizes life of an individual from the point of view of its events that can be perceived as "fateful", "bifurcation", in one word, significant, that changed the life of an individual resulting in the change of views, attitudes. In line with them, there is the so-called "inter-event" time, i.e. specific determinants that effect development of such chains as "cause-effect" or "aim-mean". The event approach unveils potential possibilities of proenvironmental activity of the subjects of environmental socialization as part of organized resonance Events.

The following personal concepts mat be determined as expected results of implementation of a multi-paradigmatic model of the system of environmental socialization of an individual in a multi-cultural educational environment: environmental responsibility, environmental sensibility, conscience, environmental friendliness, environmental culture, scientific ideology in perception and evaluation of the "human-nature-society" system, ethical norms of attitude to environment accepted by an individual, environmental moral imperatives.

\subsection{Justification of a multi-paradigmatic model for environmental socialization of an individual in a multi-cultural educational environment.}

determined: methodology, context, principles of the model development, methods and forms, criteria and indicators of the level of environmental socialization of an individual in the process of application of environmental imperatives, actualised national values in a multi-cultural educational environment;

regularities of development and implementation of the system of environmental socialization of an individual in a multi-cultural educational environment in various paradigmatic models have been determined;

environmental imperatives of ethno-cultural experience of a multi-cultural educational environment have been determined;

innovative transformation of educational environment at the stages of actualization, recovery and accumulation of an individual's experience in interrelation with the social and natural environment.

\subsection{Results of the conducted research}

1. The methodology for the research of the social and educational problems of environmental socialization of an individual based on actualization of national values and meanings has been developed;

2. The directions of the research, objective and tasks have been determined; the ideology of the research has been justified;

3. Contradictions, factors preventing efficient development of the educational system of environmental socialization have been determined;

4. The final stage of the research regarding all trends of the multi-paradigmatic model (existential, pragmatic, resonance-synergetic) has been completed aiming at determination of the initial level of environmental socialization of the learners;

5. The educational potential of ethno-cultural experience of a multi-cultural educational environment has been determined;

6. The mechanisms of interrelation and inclusion of social institutions in the process of environmental socialization in a multi-cultural educational environment have been developed;

7. The concept of existential model of environmental socialization of learners, concept of pragmatic model of environmental socialization of learners, concept of resonance-synergetic model of environmental socialization of learners have been theoretically justified;

8. A scientifically justified, reproducible multi-paradigmatic model of the system for environmental socialization of an individual in a multi-cultural educational environment has been developed.

\section{Conclusions}

The conceptual multi-paradigmatic model for environmental socialization of an individual in a multi-cultural educational 
environment is represented by the following grounds:

the system of paradigms is considered a mean of achievement of an objective at each stage of education, provides for obtaining of the result in the process of integrative implementation of an aggregate of paradigms; the structure of each paradigmatic model has its own basic foundation reflecting essential integrity of the elements of the common system: environmental, ethno-environmental values, essences, attitudes, mechanisms;

each paradigmatic model is self-valuable, autonomous although each of the paradigms is in the state of complementarity, that results in the integrative state of the educational environment; however, exclusion of one element of the system of environmental socialization of an individual will result in violation of the principle of parity between nature, human and environment;

conceptual paradigmatic model for environmental socialization of an individual is developed on the basis of the system of methodological approaches allowing to determine educational principles and their hierarchy.

The multi-paradigmatic model of the system of environmental socialization of an individual in a multi-cultural educational environment includes conceptual paradigmatic models: existential model for environmental socialization of an individual in an educational environment; pragmatic model for environmental socialization of an individual; resonancesynergetic model for environmental socialization in the context of integration tendencies in a multi-cultural, socially differentiated Russian society.

The objectives for further researches may be as follows:

development of innovative technologies for training and improvement of qualification of education personnel on organization of environmental socialization on the basis of ethno-cultural experience in a multi-ethnical educational environment and practical implementation at educational institutions;

development of conceptual approaches for organization of environmental education on the basis of a multiparadigmatic approach;

development of the system of methodological means for implementation of a multi-paradigmatic model for environmental socialization in a multi-cultural educational environment.

\section{References}

Autleva, A.N. (2013). Rezonansnyi mehanizm sotsializatsii lichnocti v usloviyah polikulturnogo obrazovatelnogo prostranstva [Resonance Mechanism for Socialization of an Individual in a Multi-cultural Educational Environment]. ESSJ European Social Science Journal. - Moscow: International Research Institute - No. 9 (36). Vol. 2, pp. 91 - 102 [in Russian].

Berdyayev, N.A. (1990). Smysl tvorchestva (Opyt opravdaniya) [Essence of Creativeness (Experience of Justification) (p.173). Moscow: Mysl [in Russian].

Bibler, V.S. (1989). Dialog kultur: opyt opredeleniya [Dialogue of Cultures: Experience of Determination] (pp.34-36). Voprosy Filosofii No. 6 [in Russian].

Budanov, V.G. (2003). Printsipy sinergetiki i upravleniya krizisom. Sinergeticheskaya paradigma. Chelovek i obschestvo v usloviyah nestabilnosti [Principles of Synergetics and Crisis Management. Human and Society under Conditions of Instability]. - Moscow: Progress-Traditsiya [in Russian].

Chermit, K.D., Autleva, A.N., Buzarov, K.I. (2014). Ekologicheskaya sotsializatsiya lichnosti v sovremennom prostranstvennovremennom kontinuume [Environmental Socialization in Modern Space and Time Continuum]. Bulletin of Adygeyskiy State University: quarterly scientific journal. Educational Sciences. - Maykop. No.4.

Dewey, J. (1921) Vvedeniye v filosofiyu vospitaniya [Introduction to the Philosophy of Education] (p.62). Moscow: Izdatelstvo TsK Vseros. Soyuza Rabotnikov Prosvescheniya [in Russian].

Federalnyi zakon "Ob Obrazovanii v Rossiyskoy Federatsii" [Federal law "On Education in the Russian Federation"] dd. 29.12.2012 FL No. 273.

Fromm, E (2009). To Have or to Be. AST.

Heidegger, M. (1988). Letter on Humanism. Problem of Human in Western Philosophy. Moscow.

Ikonnikova, N.I. (2001). Ekzistentsyaly lichnosti i paradigmy ekologicheskogo obrazovaniya. Filosofiya ekologicheskogo obrazovaniya [Existentials of an Individual and Paradigms of Environmental Education. Phylosophy of Environmental Education]. Edited by Liseyev, I.K. - Moscow: Progress-Traditsiya [in Russian].

Kolesnikova, I.A. (1999). Pedagogicheskaya realnost v zerkale mezhparadigmalnoy refleksii [Educational Reality in the Mirror of Interparadigmatic Reflexion]. - St. Petersburg: GUPM [in Russian].

Makarenko, A.S. (1984). Pedagogicheskiye sochineniya [Educational Compositions]. vol. 8, Lectures on Education. - Moscow [in Russian].

Makayev, V.V. (1999). Polikulturnoye obrazovaniye - aktualnaya problema sovremennoy shkoly [Multi-cultural Education - Actual Problem of a Modern School] (pp.3-10). Pedagogika, No. 4 [in Russian].

Moiseyev, N.N. (1995). Sovremennyi antropogenez i tsivilizatsionniye razlomy: ekologo-politologichesliy analiz [Modern Anthropogenesis 
and Civilisation Faults: Environmental and Politological Analysis] (pp.43-56). Sotsialno-Politicheskiy Zhurnal [Socio-Political Journal]. No. 5 [in Russian].

Peirce, Ch.S. (2000). Selected Philosophical Writings. - Moscow.

Prohovnik, O.A. (2006). Kulturno-antropologicheskiy krizis i noviye zadachi obrazovaniya v epohu postsovremennosti [Cultural and Anthropological Crisis and New Objectives of Education in the Era of Post-modernity]. - Rostov-on-Don [in Russian].

Putin, V.V. (2013). Report at Valday Discussion Club. htt://ru - an.info/nevs/2555 [in Russian].

Reimers, N.F. (2000). Ekologiya: teoriya, zakony, pravila, printsipy, gipotezy [Ecology: Theory, Laws, Rules, Principles, Hypothesis]. Moscow: Prosvescheniye (1994) [in Russian].

Rozhkov, M.I. (2000). Organizatsiya vospitatelnogo prostranstva v shkole [Organization of Educational Environment at Schools]: study guide for students of higher educational establishments. -Moscow: Vlados [in Russian].

Sartre, J.P. (1990). Existentialism is Humanism. Dusk of the Gods (pp. 315-345). - Moscow: Politizdat

Shatskiy, S.T. (1980). Izbranniye pedagogicheskiye sochineniya [Selected Pedagogical Writings]. - Moscow: Pedagogika

Soroka-Rosinskiy, V.N. (1996). Vospitaniye kak pedagogicheskoye yavleniye. Obsschiye zakonomernosti i printsipy vospitaniya [Education as Pedagogical Phenomenon. General Laws and Principles of Education] (p.34). Pedagogika [in Russian].

Suprunova, L.L. (2014). Polikulturnoye obrazovaniye v sovremennoy Rossii. Nravstvennost. Kultura. Sovremennost. Eticheskaya Mysl [Multi-cultural Education in Modern Russia/Morality. Culture. Modernity. Ethical Idea] (pp.16-58). - Moscow [in Russian].

Yadov, V.A. (2006). Sovremennaya teoreticheskaya sotsiologiya kak kontseptualnaya baza issledovaniy rossiyskih transformatsiy [Modern Theoretical Sociology as a Conceptual Basis for Research of Russian Transformations]. - St. Petersburg: Intersotsis [in Russian]. 